\title{
Casa Suindara: Formação, experimentação e construção no habitat rural
}

\author{
PERRIN, Anaïs Guéguen ${ }^{1}$ \\ FERREIRA, Thiago Lopes ${ }^{2}$ \\ ${ }^{1}$ HABIS, IAU,USP, São Carlos, Brasil e AE\&CC, ENSAG, Grenoble, França. anaisgueguen@gmail.com \\ 2HABIS, IAU,USP, São Carlos, Brasil e AE\&CC, ENSAG, Grenoble, França. thi.lopes.ferreira@gmail.com
}

\section{Resumo}

A Casa Suindara é o resultado de uma experiência de extensão universitária e popular, realizada nas dimensões do curso CanteiroEscola, onde a partir da produção de uma habitação familiar dentro de um assentamento rural de reforma agrária, práticas coletivas, dialógicas e sustentáveis de concepção e realização do projeto arquitetônico foram experimentadas e analisadas. Os processos de aprendizagem e construção de conhecimentos ocorreram complementar e simultaneamente às práticas construtivas e ao desenvolvimento de tecnologias sociais, mediante ao uso de materiais locais, naturais e de recuperação. Nesta perspectiva, a articulação entre o mundo acadêmico e a realidade social do assentamento rural proporcionou a aproximação e a interação entre os conhecimentos científicos, técnicos e populares. A família moradora, para além da participação no processo, revelou-se protagonista na ação e agente formadora dos participantes no canteiro de obras. Este trabalho apresenta brevemente o processo de realização do canteiro-escola, analisando sua experiência a partir das dimensões formadora e produtiva, onde os processosde aprendizagem se desenvolvem na forma de trabalho social, que por sua vez, se fundamenta enquanto princípio educativo.

Palavras-Chave: canteiro-escola; habitação popular; assentamentos rurais, tecnologias sociais.

\begin{abstract}
Suindara House results from an experiment in social and university extension, within the context of a design build program, in which, from the production of family housing in an agrarian reform rural settlement, practices of architectonic conception and execution that can be classified as collective, dialectic and sustainable, were experimented and analysed. The processes of learning and knowledge building occurred complementarily and simultaneously to the constructive practices and to social technologies development, performed based on the use of local, natural and reused materials. From this perspective, the articulation between the academic world and the social reality of the rural settlement provided the rapprochement and interaction between scientific, technical and popular knowledge. Beyond involvement in the process, the resident family revealed itself to be a protagonist in the action and a training agent of participants on the building site.This work briefly presents the execution process of the design build program, analysing the experience through productive and educational dimensions, where the training process is realised through social work, which in turn is established as an educational principle.
\end{abstract}

Key-words: design build program; popular housing; rural settlements; social technologies. 


\section{Introdução}

Este trabalho aborda uma experiência de extensão universitária e popular realizada dentro de um assentamento rural de reforma agrária ${ }^{1}$, local de construção de um canteiro de aprendizagem técnica, trocas sociais $\mathrm{e}$ produção do habitat. Esta perspectiva foi inserida nas dimensões do curso CanteiroEscola $^{2}$, espaço de trabalho social onde os processos de aprendizagem e construção dos conhecimentos ocorrem simultânea e complementarmente às diversas práticas construtivas e ao desenvolvimento de tecnologias sociais, mediante o uso de materiais locais, naturais e/ou de recuperação.

A aproximação entre o mundo acadêmico e a realidade social deste assentamento foi estabelecida a partir do desafio de conceber e produzir coletivamente uma habitação popular para uma família moradora da comunidade. Esta habitação tornou-se assim uma ferramenta para a constituição de um espaço de trabalho onde pessoas de diferentes classes sociais, de formação e nacionalidades diversas pudessem compartilhar o mesmo processo produtivo, com seus questionamentos e considerações, cada um com seu perfil e suas habilidades.

Localizado no município de São Carlos, estado de São Paulo, a Comunidade Agrária Nova São Carlos é um assentamento rural oficialmente reconhecido pelo Estado brasileiro em 2009, cerca de um ano após a ocupação da área e o início do acampamento. Neste território rural, de

\footnotetext{
1 Assumimos como referência a noção genérica de assentamento rural tecida por Sônia Bergamasco e Luís Norder (1996). Estes, consideram os assentamentos rurais como a "criação de novas unidades de produção agrícola, por meio de políticas governamentais, visando o reordenamento do uso da terra em benefício de trabalhadores rurais sem terra ou com pouca terra, envolvendo também a disponibilidade de condições adequadas ao uso da terra e, o incentivo à organização social e à vida comunitária."

2 O Canteiro-Escola é um curso coordenado pelo laboratório de pesquisa HABIS (IAU/USP São Carlos) desde 2008, cujo objetivo é reunir, no mesmo espaço didático, os conhecimentos próprios aos meios acadêmicos e os conhecimentos práticos dos profissionais da construção civil. Esta quarta edição do curso se intitulou "Canteiro-Escola: Produzindo uma habitação popular com técnicas construtivas em madeira e terra".
}

aproximadamente 1.150 hectares, 83 famílias de agricultores vivem hoje com dificuldades econômicas e estruturais, distribuindo-se em lotes cujas áreas variam entre 7 e 12 hectares cada. São pessoas que convivem e resistem às condições dispostas em suas realidades sociais, buscando acessar certos créditos financeiros que possibilitem viabilizar e assegurar sua reprodução social e $\quad$ desenvolvimento da comunidade. Vale ressaltar que dentre as inúmeras dificuldades existentes carecem iniciativas que atendam a temas relacionados diretamente à produção do habitat, tais como a construção de casas, o acesso à água, ao saneamento básico, a assistência técnica necessária, entre outros.

As atividades acadêmicas ganharam forma através de dois cursos universitários promovidos pelo Instituto de Arquitetura e Urbanismo (IAU/USP) e organizados pelo grupo de pesquisa HABIS em parceria com 0 laboratório de pesquisa Cultures Constructives (ENSAG-França). As dinâmicas desenvolvidas abrangeram atividades realizadas tanto na Universidade quanto no assentamento rural.

\section{Sobre o contexto habitacional rural}

Conforme os dados do último recenseamento demográfico brasileiro realizado pelo Instituto Brasileiro de Geografia e Estatística (IBGE), no ano de 2010, o Brasil possui 190.755.799 habitantes, sendo que $15,64 \%$ desta população vive em áreas rurais ${ }^{3}$. De acordo com estas estatísticas, a região sudeste do país (região deste projeto) concentra cerca de 80.364.410 habitantes, sendo que $92,95 \%$ desta população vivem em áreas urbanas.

No mesmo ano, a Fundação João Pinheiro

\footnotetext{
${ }^{3}$ Embora os dados sejam oficiais, existe um grande debate em torno da metodologia utilizada na conceituação dos territórios urbanos e rurais, na medida em que as classificações nem sempre refletem as características espaciais e demográficas das áreas a que se referem. Segundo Alexandre VALADARES (2014), a porcentagem da população rural brasileira poderia ser elevada a mais de $22 \%$ da população absoluta, se o método estatístico conjugasse aos critérios referentes ao número de habitantes, a densidade populacional e a natureza da ocupação de trabalho das pessoas.
} 
divulgou uma pesquisa ${ }^{4}$ que aponta um déficit habitacional na ordem de 6,94 milhões de unidades no Brasil, correspondente a 12,1\% dos domicílios do país. Segundo o estudo, a região Sudeste concentra $38 \%$ desse déficit, ou seja, cerca de 2,674 milhões de unidades. Mais da metade deste valor (1,495 milhões) está situada no estado de São Paulo, sendo que as áreas rurais comportariam um déficit de cerca de 31,250 mil domicílios.

Atualmente, as políticas públicas relativas aos créditos financeiros destinados à construção de habitações populares rurais estão vinculadas ao Programa Nacional de Habitação Rural PNHR, articulado por sua vez, ao Programa Federal "Minha Casa Minha Vida", dentro da modalidade "Minha Casa Minha Vida Rural", cujo banco Caixa Econômica Federal é o agente financeiro e gestor operacional.

Este programa está voltado para a população que vive no meio rural, como os agricultores familiares, trabalhadores rurais, comunidades tradicionais, entre outros. Regulamentado pelo Ministério das Cidades, suas ações englobamtanto construções novas quanto reformas de casas antigas. Para as famílias moradoras de assentamento rurais, o montante destinado na construção de uma nova habitação é de $R \$ 28.500,00$ reais e, para reformas, de $R \$ 17.200,00$ reais. Deste valor, até $35 \%$ pode ser utilizado com o pagamento de mão de obra.

Para uma melhor compreensão das possibilidades construtivas oferecidas pelo crédito habitacional, propomos o seguinte raciocínio rápido: partindo do custo médio por m2 de construção $\left(C^{2} B^{6}\right)$ referente ao padrão

\footnotetext{
4 Informações obtidas do "Déficit habitacional municipal no Brasil, 2010", documento produzido pela Fundação João Pinheiro.

${ }^{5}$ As informações foram obtidas no site do Banco Caixa Econômica Federal. Consultado em 09/07/2014.

http://www1.caixa.gov.br/gov/gov_social/munici pal/assistencia_tecnica/produtos/repasses/pnhr_ ogu/index.asp

${ }^{6} 0$ Custo Unitário Básico (CUB) consiste no principal indicador dos custos do setor brasileiro da construção civil e determina o custo global da obra de maneira aproximativa à realidade do mercado. Ele é calculado pelos Sindicatos da Indústria da Construção Civil
}

de interesse social (padrão mais baixo indicado), estimado em $\mathrm{R} \$ 778,76$ reais, com o montante de $R \$ 28.500,00$ reais poderiam ser construídas novas habitações com cerca de 36 $\mathrm{m}^{2}$.

Este cálculo embora não inclua os custos indiretos existentes na produção dos canteiros de obras e inclua um valor de mão de obra um pouco maior $(40 \%)$ do que o valor autorizado pelo financiamento serve para indicar, de maneira global, o quadro habitacional estabelecido pelos programas de governo para os assentamentos rurais de reforma agrária. Como resultado, são frequentes as casas de baixa qualidade, geralmentepequenas para 0 tamanho das famílias ou ainda com maiores dimensões, mas interrompidas antes do término, devido à falta de recursos financeiros.

Neste sentido, deve-se atentar para o fato das condições, regras, normas e padrões impostosno acesso à moradia revelarem as contradições existentes entre o direito a habitar e a dificuldade em fazê-lo. A produção do habitat se afasta cada vez mais de sua realização enquanto fruto das disponibilidades dos materiais locais, prioridades, desejos e valores familiares, alinhados às características culturais dos grupos sociais, e passam a ser rigorosamente pautadas por formas heterônomas de satisfação das necessidades, balizadas por custos operacionais e por interesses financeiros e de classe.

É no âmbito da contribuição à reflexão e ação de novas formas de concepção e produção do habitat rural que este projeto se realiza. Sua inserção em um assentamento rural peri-urbano orienta a compreensão do território a partir das relações dialéticas de complementaridade entre os espaços rurais e urbanos, revelando modalidades de funcionamento que potencializam novas possibilidades de interação e experimentação social e produtiva.

(Sinduscon) de todo o país e sua variação percentual mensal tem servido como mecanismo de reajuste de preços e principal indicador dos custos das construções, em função de diferentes padrões de qualidade e diferentes tipos de construções. 


\section{3. $O$ assentamento e a pesquisa-ação}

A aproximação do grupo de pesquisa com as famílias do assentamento se deu em um momento histórico importante na comunidade, período em que estas estavam começando a construir suas casas. A entrada no assentamento ocorreu a partir de uma família moradora, que se disponibilizou a apresentar os representantes da comunidade, além de estimular as pessoas a participarem de um grupo de trabalho relacionado às construções das casas.

O interesse orientava-se para a constituição de um processo coletivo de discussão sobre as dificuldades encontradas pelas famílias na produção de suas moradias, e assim, na elaboração de um programa de açõesobjetivando melhorar as condições observadas.

Em função da existência de um antigo galpão no assentamento, espaço coletivo utilizado para reuniões e encontros sociais, as primeiras atividades tiveram como objetivo central, refletir coletivamente sobre a organização de cursos de formação profissional em diferentes técnicas construtivas, a partir da reforma do galpão. As dificuldades técnicas e de planejamento das obras seriam discutidas e experimentadas durante as práticas construtivas.

A ideia era a de que a formação técnica realizada ao longo do processo de reforma do galpão poderia ser reaplicada pelas famílias na construção ou reforma de suas próprias casas.

Figura 1: Localização do assentamento Comunidade Agrária Nova São Carlos. Situado no interior do estado de São Paulo, encontra-se na zona industrial da cidade de São Carlos, distante $8 \mathrm{~km}$ de seu centro. Cobre um território de 1.158,5 hectares dividido em quatro glebas pela Estrada Domingos Innocentini (sentido norte-sul) e por uma linha de alta tensão (sentido oeste-sul). À leste, a comunidade é delimitada por uma via férrea. O lote onde se desenvolve o projeto está marcado em vermelho no mapa à direita da figura.

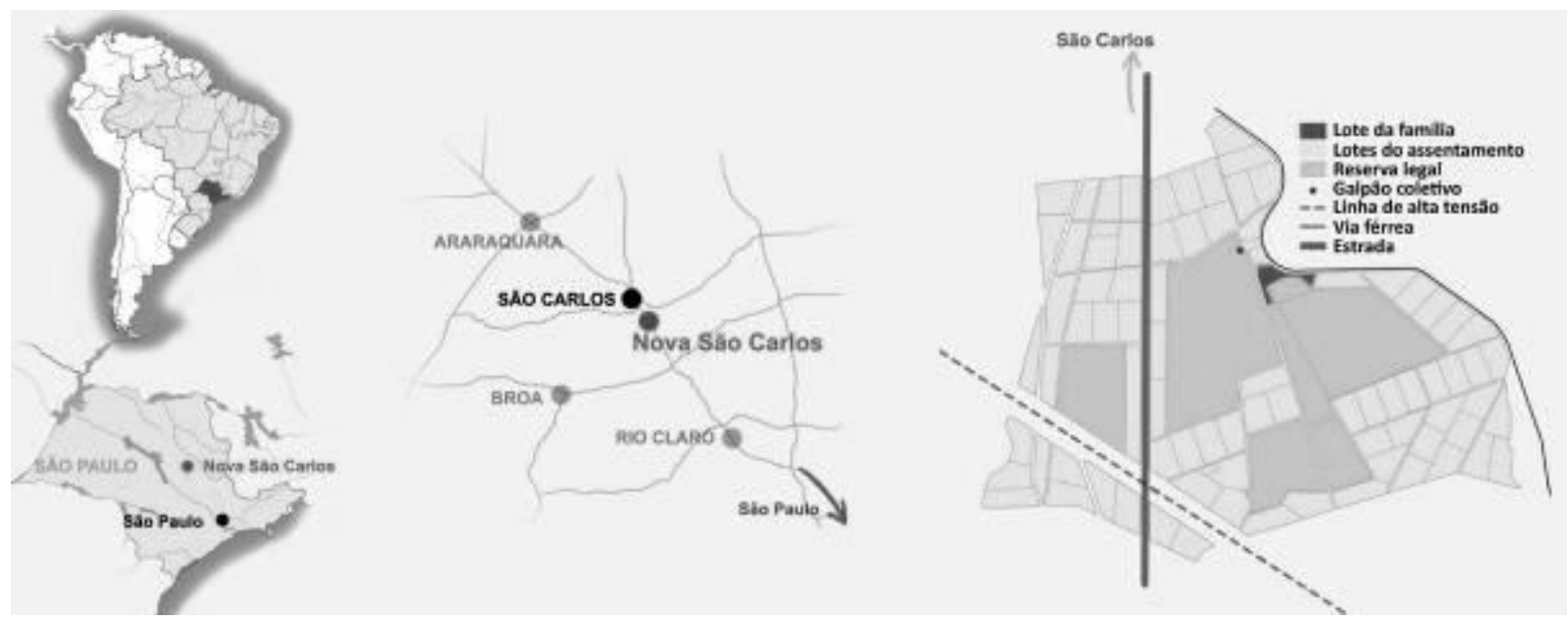

Por um conjunto de fatores de ordem social, cultural e política, as atividades não tiveram o impacto e os resultados esperados. As famílias, dentro de seus contextos particulares, não apresentaram condições, tempo ou interesse para a realização de uma atividade coletiva de reforma do galpão a partir de cursos de formação. E dentro do grupo de pesquisa, por sua vez, não haviam, naquele momento, condições estruturais e humanas para a realização de um trabalho de maior envergadura, a partir da organização e acompanhamento social junto a cada uma das famílias. Desta forma, as estratégias do projeto transformaram-se e novos rumos de atuação foram planejados.

O processo de análise do contexto existente a partir da participação na realidade trabalhada possibilitou definir novas orientações e escolhas a partir de uma compreensão mais aprofundada e dos fatores influentes. As reflexões coletivas orientavam as ações para a realização de uma 
prática concreta que pudesse fortalecer nossa inserção na comunidade e servir como referência para a sensibilização de outras famílias, alavancando posteriormente novas práticas coletivas no assentamento. A estratégia escolhida passou pelo compromisso estabelecido junto à família com a qual houve o ingresso inicial na comunidade.

A metodologia de ação adotada centra-se na construção de um processo formador orientado pelo método de pesquisa-ação ${ }^{7}$ que torna-se 0 eixo central da articulação entre o espaço acadêmico e o espaço rural do assentamento. As relações estabelecidas entre o grupo de participantes e a família, através de práticas dialógicas, propõem aos envolvidos uma atuação proativa, a partir de suas percepções enquanto sujeitos atuantes, que pensam e agem em direção a uma dimensão crítica do projeto arquitetônico e de seus sistemas construtivos. Ademais, o processo de reflexão e ação coletiva necessita, constantemente, adaptar-se ao imprevisível presente no dia-adia, e se organizar e reorganizar a partir das situações relevantes que emergem regularmente deste processo.

Nesta perspectiva, os diálogos foram amadurecendo e delineando os acordos que estabeleceram uma lista de direitos e deveres de todos os participantes (família, inscritos e equipe de pesquisa). $O$ princípio central deste experimentar produtivo estava focado no desafio de se conceber uma habitação a partir da produção local de tecnologias, oriundas das condições, recursos, conjunturas e formas existentes e criadas no lote, no canteiro e no próprio processo produtivo. Através de explicações teóricas, técnicas, conversas coletivas e ações práticas, as atividades atravessavam cada etapa de concepção e construção da nova habitação.

\section{Casa Suindara: processo coletivo de produção do habitat}

\footnotetext{
7 Para maiores informações ver autores como: Maria Amélia S. FRANCO (2005) et Khalid El ANDALOUSSI (2000).
}

A primeira fase de produção da casa Suindara ${ }^{8}$ contou com a participação de 34 estudantes e ocorreu ao longo do primeiro semestre de 2013. O calendário dos encontros teóricos e das atividades práticas foi organizado em duas vertentes. A primeira consistia em um encontro semanal na Universidade onde os estudantes organizados em grupos concebiam diferentes propostas de projetos habitacionais e de sistemas construtivos, a partir dos materiais encontrados no lote familiar, e que seriam construídos e testados durante as atividades práticas de canteiro.

Localmente, os materiais disponíveis para a construção eram a terra (arenosa com cerca de $70 \%$ entre grãos finos e médios), os eucaliptos (existentes no assentamento e região) e os paletes de madeira (descartados como resíduos pelas indústrias instaladas próximas à comunidade).

A segunda vertente, também semanal, propunha a inserção dos participantes em diferentes práticas construtivas no lote familiar de produção. Foram construídos um galpão para estocagem dos paletes de madeira e um banheiro seco que pudesse servir à família e aos participantes ao longo do curso. Em seguida, foram construídos e experimentados os sistemas construtivos propostos pelos diferentes grupos de participantes em sala de aula.

O projeto arquitetônico possuía alguns princípios norteadores. O primeiro deles indicava para o melhor aproveitamento das possiblidades de utilização dos materiais naturais e de recuperação disponíveis localmente e na região. A ideia central era incentivar o exercício de criar, experimentar e desenvolver, a partir do uso e transformação

\footnotetext{
${ }^{8}$ Esta fase ocorreu no quadro de um curso optativo do Instituto de Arquitetura e Urbanismo (IAU/USP/São Carlos) sob a organização do grupo de pesquisa HABIS em colaboração com o laboratório de pesquisa Cultures Constructives (ENSAG/França). O nome Suindara faz referência à coruja Suindara, encontrada na região e de maneira abrangente em todo o Brasil. A denominação foi dada pela própria família à sua nova habitação.
} 
dos materiais, ferramentas, recursos e inteligências disponíveis, alguns sistemas construtivos que orientassem as escolhas produtivas de cada grupo de trabalho.

Outro princípio indicava a necessidade de inserir o projeto dentro de sua realidade social, ou seja, dentro das dinâmicas que envolvem e interferem na realidade do assentamento rural. Para isso, era necessário refletir sobre certas características, valores, condições, processos históricos, entre outros elementos, presentes neste mundo rural, e em suas relações com o mundo urbano de São Carlos. As relações sociais construídas entre os participantes e a família foram fundamentais para uma melhor compreensão dos "por quês" e "como" daquela realidade, de modo a enriquecer as reflexões e escolhas de projeto.

Figura 2: As primeiras atividades realizadas proporcionaram uma melhor compreensão do contexto do assentamento e do lote. Aos poucos, os trabalhos práticos de experimentação e construção coletiva foram sendo desenvolvidos, sempre de maneira complementar ao desenvolvimento das propostas para os projetos arquitetônicos, realizados estes na Universidade.
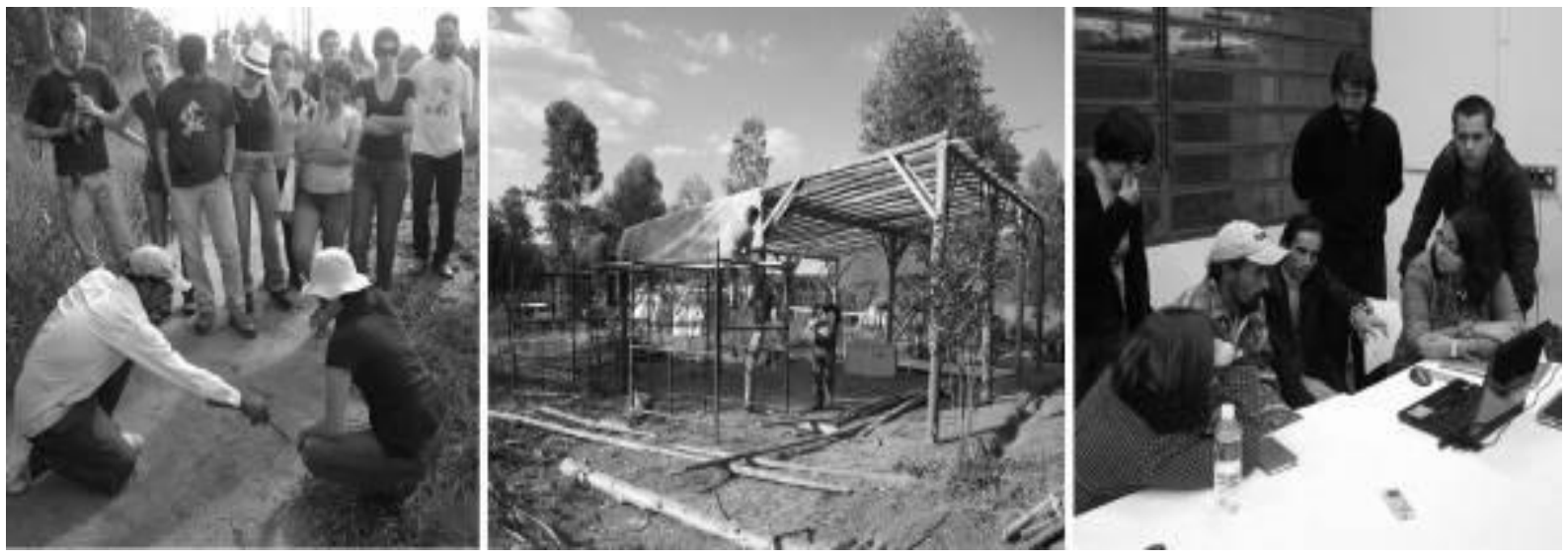

A presença da família na Universidade se deu em diferentes ocasiões onde foi experimentado o exercício do acompanhamento, das trocas de ideias e das dúvidas sobre os avanços dos projetos. Sua participação no ambiente acadêmico com a possibilidade de debater, refletir e escolher a respeito dos projetos de sua própria casa e outras questões relativas fortaleceu as relações sociais e os compromissos acordados entre o grupo de estudantes e a família, estabelecendo os acessos aos dois ambientes (universidade e assentamento) onde as reflexões e as práticas se faziam. Esta aproximação entre os conhecimentos acadêmicos e os conhecimentos populares e técnicos da realidade social foram tecendo e potencializando outras significações sobre o ato de projetar e produzir coletivamente.

Figura 3: Ao final do curso foram apresentadas, discutidas e avaliadas as propostas para os projetos arquitetônicos e os sistemas construtivos desenvolvidos no lote familiar.
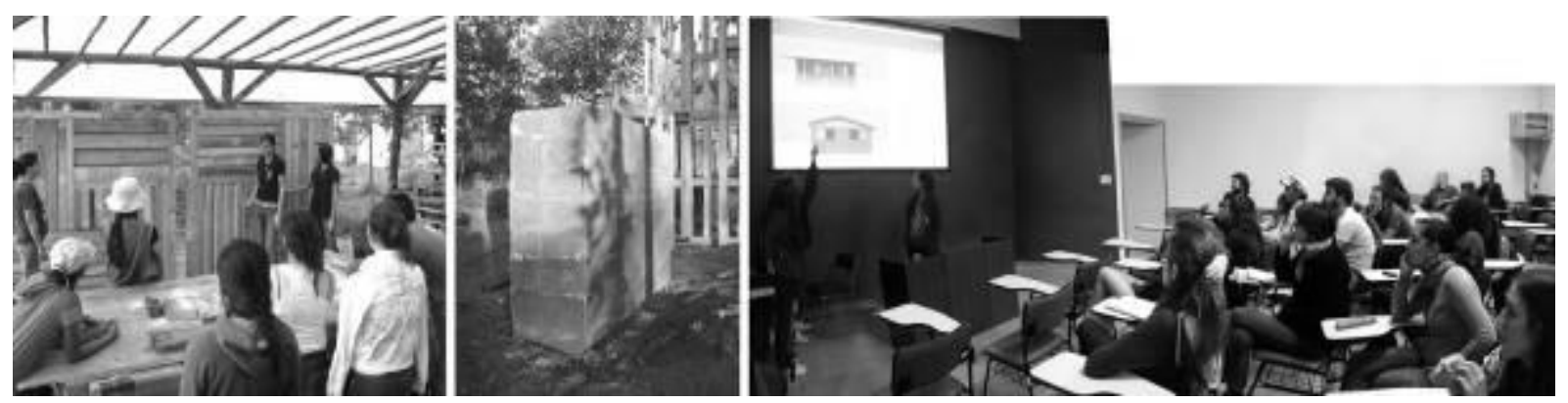
Como resultado desta fase, cinco propostas de projetos habitacionais foram desenvolvidas pelos estudantes, compatíveis com os desejos e necessidades da família, com suas condições financeiras e com o contexto ambiental do lote e do assentamento. Estes projetos foram apresentados, discutidos, analisados e deram origem ao projeto final, concebido junto com a família, a partir da tentativa de reagrupar as ideias mais pertinentes e adequadas, tanto a nível de projeto quanto dos sistemas construtivos.
As experimentações práticas resultaram, por sua vez, no desenvolvimento de cinco sistemas construtivos a partir da utilização das ripas de madeiras dos paletes descartados, por vezes consorciados com a utilização da terra do local. Foram produzidos três tipos diferentes de painéis de paredes com paletes, uma viga de madeira em perfil I, uma porta de correr e fôrmas para a produção de paredes em taipa de pilão. Todos os resultados foram apresentados eanalisados em grupo, e uma auto avaliaçãofoi feita a cerca das atividades do curso e das experiências vividas.

Figura 4: Perspectiva do projeto final da casa Suindara com seus principais elementos construtivos e a planta baixa do projeto, concebido a partir de dois módulos paralelos de $4 \mathrm{~m} \times 12 \mathrm{~m}$, com sua organização interna, orientação dos cômodos e usos propostos.

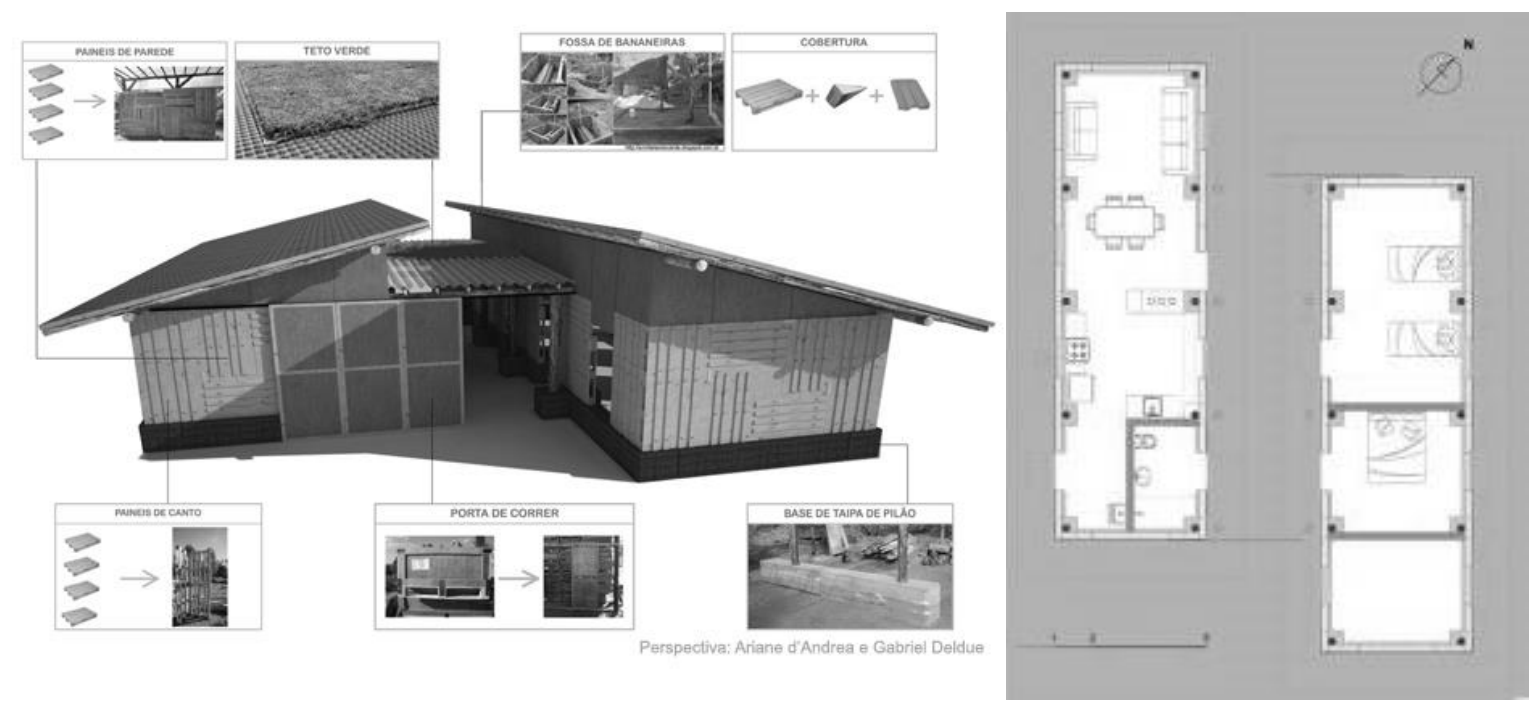

O projeto arquitetônico da casa Suindara é composto por dois módulos retangulares separados, paralelos e desencontrados unidos por um espaço central coberto de acesso a cada cômodo da casa, e que pode ser aberto ou fechado em função das atividades da família. No módulo orientado a leste estão dispostos os quartos, e no módulo oeste estão organizados os demais cômodos, sendo estes: a sala, cozinha, banheiro e dispensa. $O$ projeto modular permite a evolução ao longo do tempo com o acréscimo de novos cômodos ou a reorganização interna dos mesmos. Sendo arenosa a terra encontrada no lote, as fundações e as bases da construção foram feitas com a terra estabilizada com cimento, a partir da técnica da taipa de pilão. A estrutura da casa é de troncos roliços de eucaliptos, e tanto as paredes de fechamento quanto os painéis de cobertura foram produzidos a partir da reutilização dos paletes de madeira descartados pelas fábricas do entorno. Os tratamentos das águas negras e cinzas serão realizados através de processos biológicos de filtragem e purificação das águas.

Uma vez concluída a etapa de realização do projeto arquitetônico, foi iniciada a segunda fase da casa Suindara, organizada em dimensões mais amplas e aberta ao público de uma maneira geral, entre estudantes, profissionais e 
pessoas interessadas ${ }^{9}$. Sob a forma do curso de extensão universitária Canteiro-Escola, as atividades tiveram como objetivo dar continuidade à primeira fase do projeto, promovendo a construção da casa a partir de diferentes Oficinas referentes a cada etapa construtiva.

Cada Oficina tornou-se palco da aproximação entre as discussões teóricas e suas práticas construtivas. Passando pelas fundações, estruturas, coberturas e painéis das paredes, os participantes experimentaram, desenvolveram e realizaram os diferentes processos produtivos de forma estruturada e articulada com os processos de formação.

Notou-se ali, a construção plural dos papéis assumidos por cada um dos participantes ao engajarem-se nas responsabilidades colocadas em prática. Foram ao mesmo tempo aprendizes e facilitadores, construtores e planejadores. Assim, discutiam os projetos de arquitetura, pilavam a terra, descascavam os eucaliptos, desmontavam os paletes, experimentavam sistemas construtivos, organizavam-se em grupos, discutiam as atividades, as dificuldades encontradas, o tempo necessário para a execução das tarefas, os benefícios e os riscos, questionavam as técnicas escolhidas, confraternizavam com a família, interrogavam sobre processo de reforma agrária e as condições de vida no assentamento, etc.

Notamos ali um processo de transformação em que o futuro morador se apropriava do papel de produtor de seu habitat e, para além da participação nos processos decisórios e construtivos, se revelava facilitador e instrutor nas sucessivas etapas do canteiro, orientando os participantes quanto às técnicas, os gestos, as ferramentas, as posturas, entre outras questões.

\footnotetext{
${ }^{9}$ Esta fase foi planejada a partir de um curso de difusão e de extensão universitária do mesmo Instituto de Arquitetura e da Comissão de Cultura e Extensão do IAU/USP/São Carlos. A organização do curso ocorreu através da mesma parceria entre os grupos de pesquisa Habis e CulturesConstructives/ENSAG, citados anteriormente.
}

O fato do morador, assentado rural e trabalhador da construção civil, compartilhar seus conhecimentos técnicos em uma perspectiva educadora, explicando e ensinando os gestos e as posturas específicas das etapas construtivas, para futuros arquitetos, permitiu desconstruir certas relações hierarquizadas nos processos produtivos do mercado e praticar outras formas de organização do trabalho coletivas, dialógicas, autogeridas e sustentáveis - revelando dimensões educativas e conscientizadoras do trabalho.

A importância dada às práticas construtivas, aos aprendizados, à participação e às trocas entre o grupo e a família, alimenta a apreensão e o empoderamento dos sujeitos participantes, acentuados pelo exercício de realização do trabalho coletivo. Sua inserção nas dinâmicas da realidade social amplia o potencial do trabalho, e assim como o produto realizado, seu processo ganha evidência e adquire significado crítico.

Esta dinâmica passa pelos debates acerca dos tipos e usos dos materiais de construção, de seus impactos culturais e ambientais, das relações de produção, de seus mecanismos de organização e gestão, e ainda, pela dimensão sócio-técnica dos processos de desenvolvimento tecnológico, com suas experimentações, sistematizações, aprimoramentos, produção e avaliação. 
Figura 5: Sessões de debates, explicações teóricas e práticas construtivas durante o canteiro-escola. Para cada etapa do curso foram desenvolvidos painéis pedagógicos que serviram como ferramentas de apoio às explicacões teóricas e aos debates coletivos.
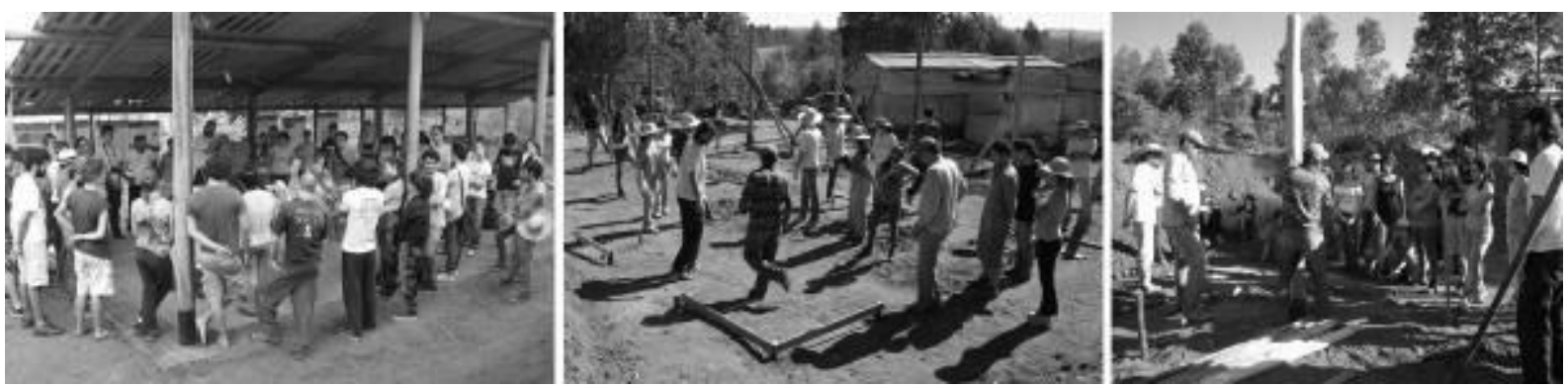

Figura 6: Através da organização coletiva os grupos realizaram os trabalhos referente à escavação e preparação das fundações da casa a partir da técnica da taipa de pilão. A terra local foi estabilizada com cimento e apiloada em camadas sucessivas dentro das fundações.
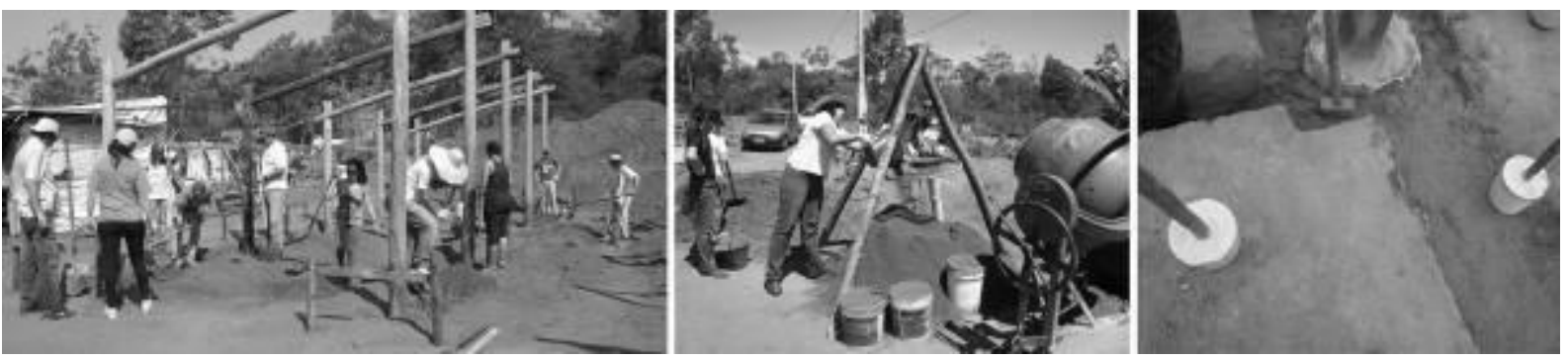

Figura 7: Os painéis de cobertura foram produzidos a partir da reutilização de paletes de madeira. Parte deles foram desmontados e suas ripas foram utilizadas na confecção das vigas laminadas pregadas, posteriormente fixadas aos paletes inteiros, constituindo assim os painéis de cobertura. A mesa de produção foi construída com madeiras de descarte doadas por uma indústria da região junto com os paletes.
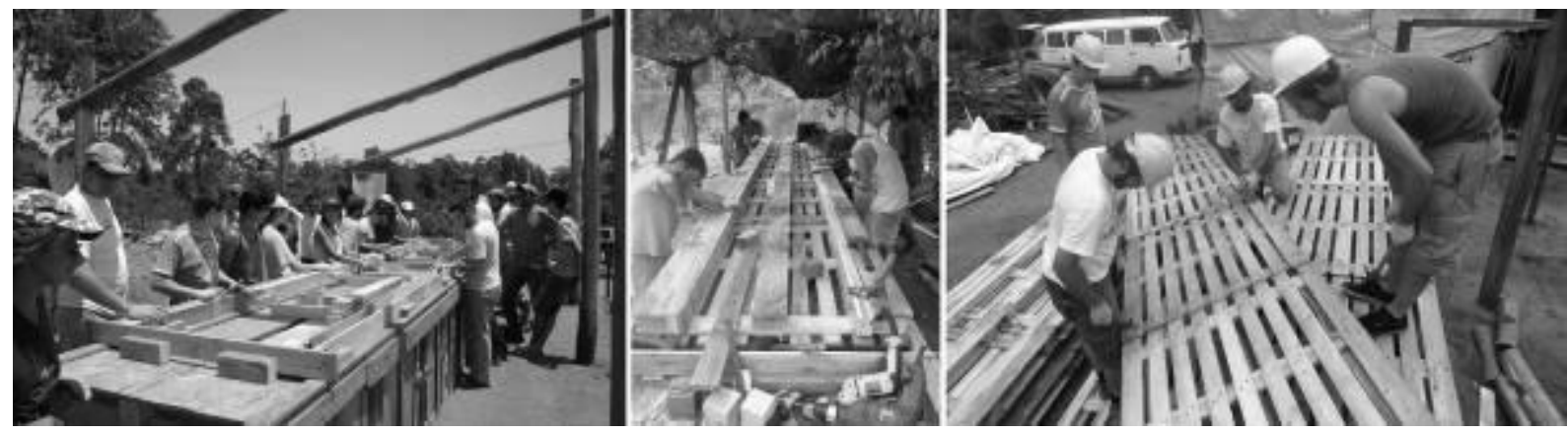

Figura 8: A base da casa foi realizada de maneira semelhante à fundação. A terra do lote foi estabilizada com cimento e apiloada dentro de fôrmas de madeira em camadas sucessivas. Primeiramente, foram realizadas as taipas em torno dos pilares da casa, seguidas pelas taipas das bases das paredes.
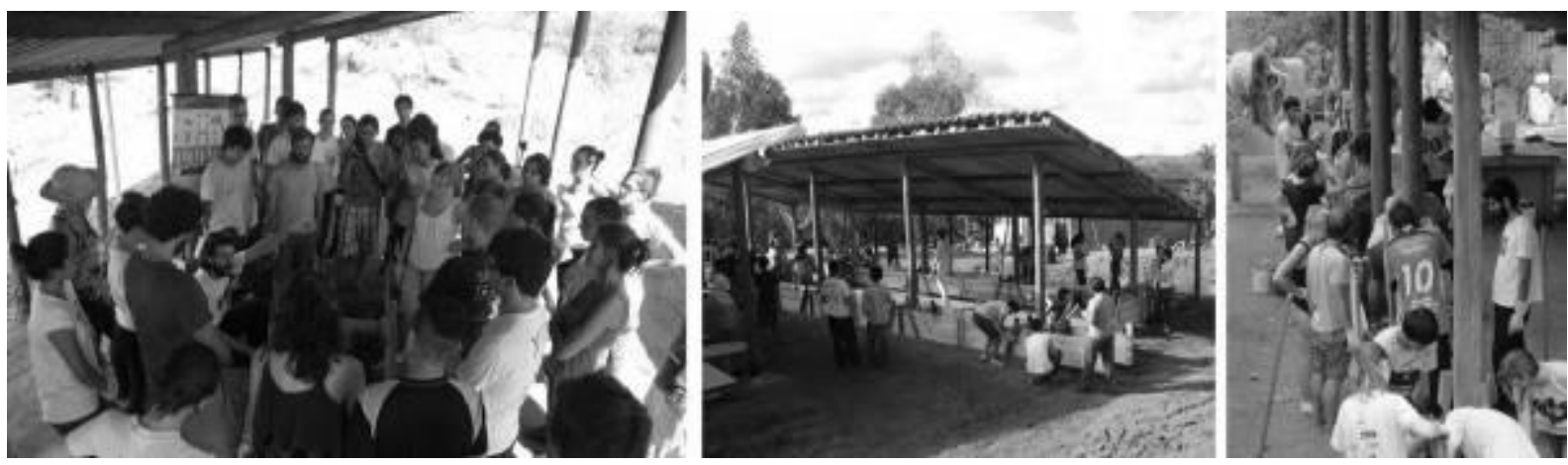
Figura 9: Base das paredes em taipa de pilão. Durante a compactação foram colocadas terras de cores diferentes que criavam variações na taipa de pilão. Também foram realizados ângulos chanfrados para limitar o desaaste dos cantos da taiba e encaixes tipo macho-fêmea na união entre as bases de taina.
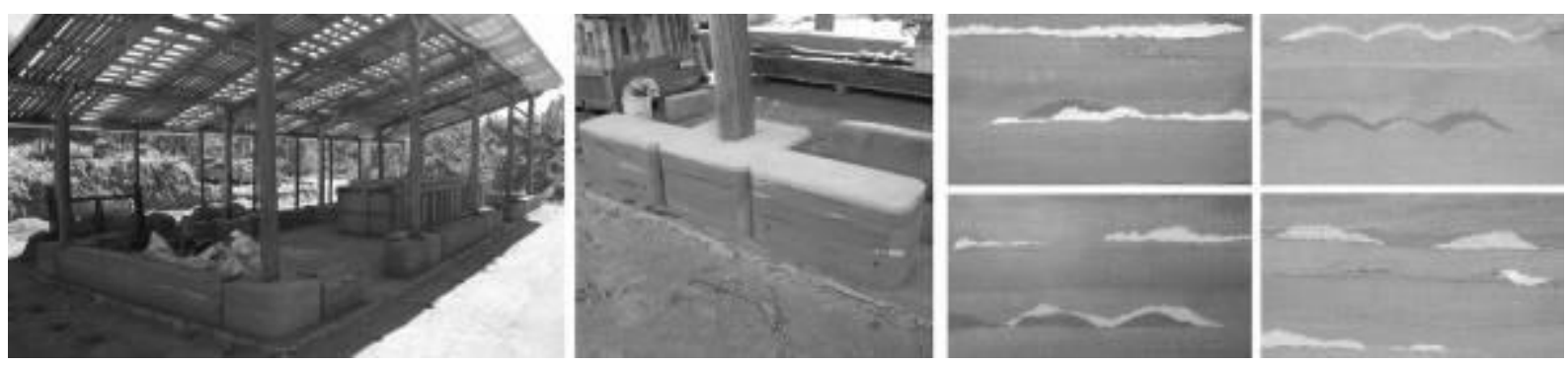

Neste contexto, são provocadas condições para a constituição de um espaço de trabalho autogerido e de produção de conhecimentos, onde as ferramentas e os diálogos se interagem e proporcionam novas criações em torno das práticas construtivas do habitat. As potencialidades transformadoras são as perspectivas reveladas na produção. Elas são fruto da participação coletiva, crítica e criativa dos participantes envolvidos.

Assim, o pensar, o projetar, o praticar e o desenvolver, foram buscar no trabalho direto entre os materiais e os capitais disponíveis, entre as inteligências construtivas e as forças de trabalho, seus elementos norteadores do processo. As tecnologias se desenvolveram fruto dos constantes diálogos entre os conhecimentos científicos, os conhecimentos técnicos e os conhecimentos populares.
O desafio de criar soluções arquitetônicas para - habitat a partir dos recursos locais disponíveis, fortaleceram os processos de formação individual e coletiva do grupo, facilitando a compreensão da produção tecnológica, para além de seus procedimentos técnicos, inseridas em processos sociais, culturais, econômicos e políticos.

Ao invés de tentar pré-estabelecer ou controlar as variáveis e as condições do lugar, torna-se necessário descobrir as peculiaridades locais e incorporá-las aos processos tecnológicos. Tornar, tanto as atividades produtivas quanto as formadoras, os pontos de partida dos processos alavancados, e assim, concentrar as análises nas situações em que a atividades ocorrem. $O$ objeto casa vira ferramenta para constituição deste processo maior, de formação humana, conectada às relações com seu contexto.

Figura 10: Realização e fixação dos painéis de parede produzidos a partir dos paletes descartados. Estes, foram desmontados, classificados, cortados e remontados sob medida. A mesa de produção foi adaptada e os grupos refletiam e construíam os painéis através de suas etapas produtivas.
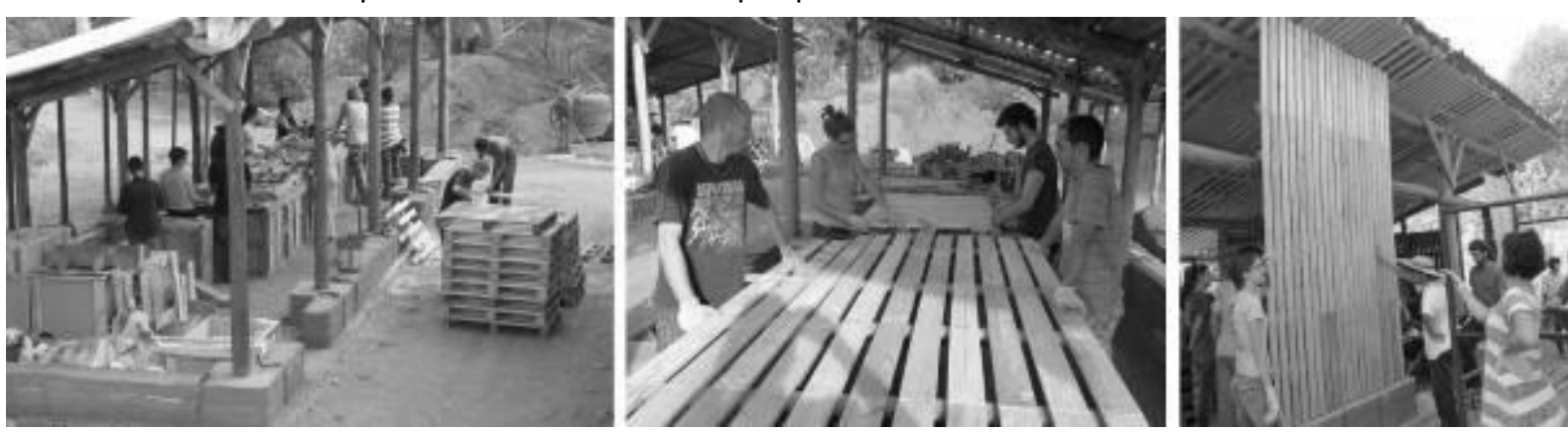
Figura 11: O acabamento externo dos painéis foi realizado com ripas de madeira dos paletes formando matajuntas externas. Do lado interno, o painel foi preenchido com terra, retida por uma trama de telas de arame e sombrite. Em seguida, foi aplicada uma camada de revestimento de terra e fibra. A fibra foi adicionada com o intuito de melhorar a aderência do revestimento nas telas e criar uma trama dentro da mistura de terra, minimizando sua retração (das argilas) após a secagem. Por cima deste revestimento foi aplicada a segunda camada de terra branca como acabamento final.
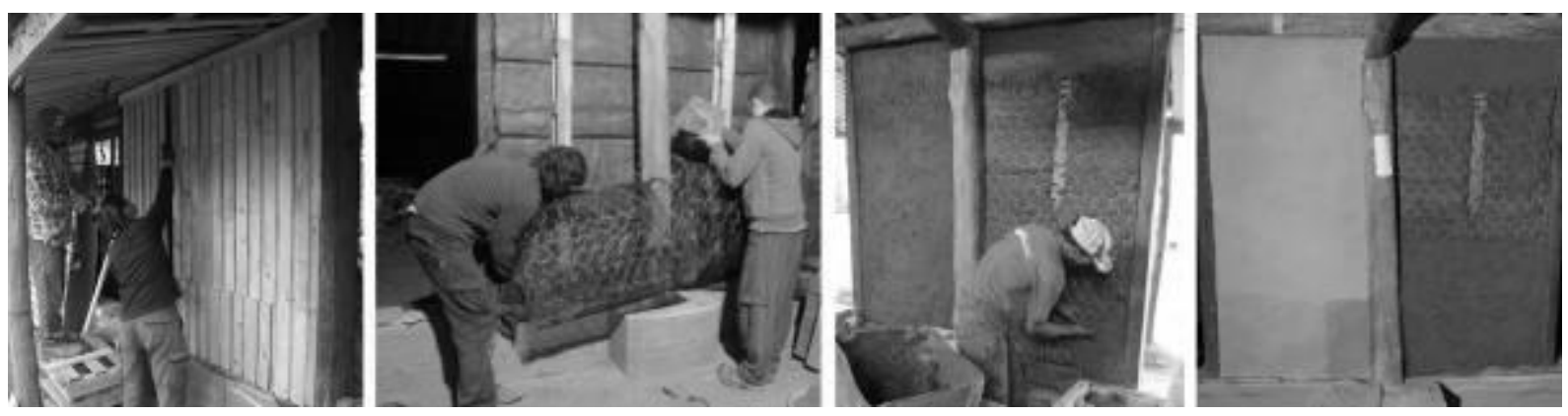

Figura 12: Vista da casa Suindara com os painéis de parede fixados, prontos para receber o preenchimento de terra e os acabamentos externos e internos da casa.
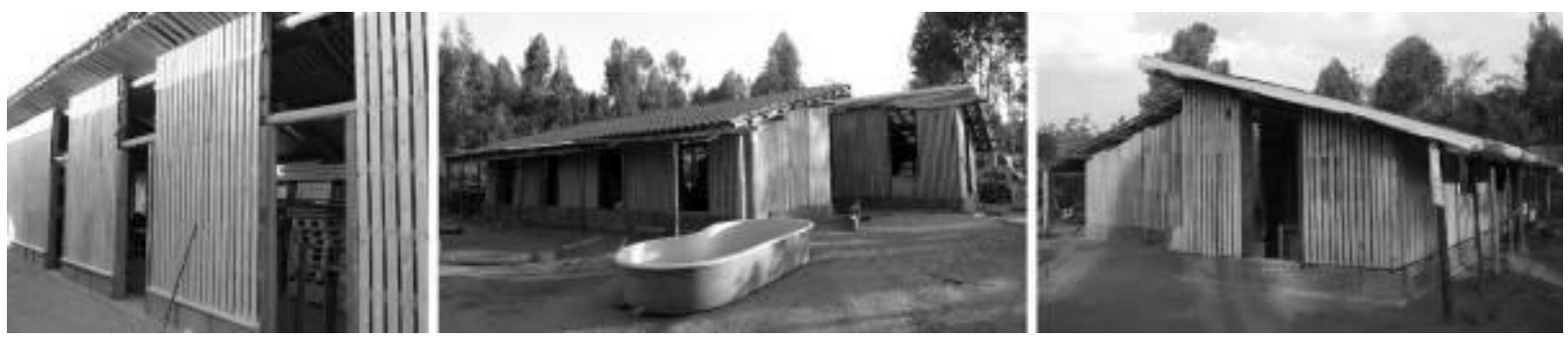

O curso Canteiro-Escola tratado neste trabalho foi organizado a partir de três oficinas. As atividades somaram 51 dias formais de idas ao assentamento, estendidas ao longo de um ano de curso. No total, 91 participantes acompanharam as atividades com uma média de 19 pessoas por dia no canteiro.

A maior parte dos participantes eram estudantes de arquitetura e engenharia ambiental. Somavam-se a eles profissionais arquitetos, engenheiros, artistas, publicitários, biólogos, entre outros. Eram brasileiros e também estrangeiros mexicanos, uruguaios, chilenos, colombianos, cabo verdianos, franceses e alemães. Desta forma, o canteiroescola configurou-se como um espaço de múltiplas culturas, diferentes idiomas, acúmulos e motivações particulares. Sua produção humanizada resulta em elemento chave para os processos questionadores da forma, conteúdo e formato dos canteiros de obras. O espaço de trabalho transformado em espaço de formação e produção coletiva de conhecimentos.

\section{Conclusões}

O desenvolvimento rural e local compreendido nas dimensões de suas novas ruralidades ${ }^{10}$, a partir das dinâmicas dos territórios urbanos e rurais, e de suas relações intrínsecas estabelecidas, inserem os assentamentos rurais de reforma agrária como elementos de suma importância nas conjunturas que marcam o mundo rural brasileiro.

Este, não mais tido como um espaço exclusivo das atividades agrícolas, mas como um território de sociabilidade complexa onde surgem cada vez mais novas redes sociais em diferentes escalas de atuação. Sérgio Leite (2004) tem destacado que mesmo reduzido ante a concentração fundiária que marca 0 caso brasileiro, os assentamentos rurais vem

${ }^{10}$ Ver autores como: Maria José CARNEIRO (2003), Maria N. WANDERLEY (2001), Roberto José MOREIRA (2007), entre outros. 
aumentando, permitindo afirmar certa "irreversibilidade" do processo. Para além da compreensão de que as políticas públicas para os assentamentos vêm a reboque da ação dos setores organizados em torno da Reforma Agrária, Leite (2004, p.110) evidencia a "necessidade de compreender melhor o significado e a dimensão que esses novos sujeitos e essas novas unidades (de produção, consumo, trabalho, moradia, lazer, vida etc.) passam a cumprir no seio da chamada questão agrária brasileira".

Ao inserir o curso de extensão universitária no mundo real do assentamento rural, se oferece aos universitários e assentados uma série de instrumentos que contribuem para uma melhor compreensão das relações entre o rural e o urbano, flexibilizando ainda mais suas fronteiras e misturando os dois espaços. Neste processo, são experimentadas ações de interação e complementaridade entre o mundo acadêmico e a realidade social, aproximando a pesquisa e a ação, a teoria e a prática, quem concebe de quem constrói.

O canteiro-escola configura-se como um ambiente onde os processos produtivos $\mathrm{e}$ formadores se entrelaçam, buscando conciliar os diferentes interesses e pontos de vistas, propondo e discutindo as transformações e imprevistos, cujo processo mesmo se dinamiza constantemente. $O$ canteiro ganha a forma de uma plataforma de trabalho e formação, mediada por diferentes sujeitos engajados no desafio de se pensar e realizar outros modos de produção do habitat rural.

A experimentação assume grande importância neste exercício de redescobrir e reinventar os modos de habitar, e as perspectivas metódicas de ação e produção dos conhecimentos vão acompanhando, orientando, modificando e sendo modificadas, pelo próprio realizar do processo formativo.

Por sua natureza, o canteiro-escola potencializa a aprendizagem durante a realização prática. Por sua dinâmica, incita a autonomia na organização e a autogestão no trabalho. Por seu caráter participativo, estimula a curiosidade crítica durante a apreensão e o desenvolvimento das atividades.

Potencializando os questionamentos das soluções técnicas, provocando a criatividade dos participantes por soluções viáveis e condizentes com a realidade, alimentando as práticas de trabalhos em grupos, da experimentação livre, da materialização das ideias, e da reflexão crítica dos processos realizados, o canteiro-escola consiste numa prática formadora que possui sua realidade concreta, com seus tempos e formas manifestas, em constante transformação e adaptação no arranjo dialético entre as conjunturas dispostas e as possibilidades operadas.

Nesta experimentação coletiva de produção do habitat popular rural, os espaços de debates, aprendizagens e tomadas de decisões ocorrem no próprio espaço de moradia e trabalho, entre a família e os participantes. A inserção da família no centro do processo de análise das necessidades e tomadas de decisões, estabeleceu um modo de organização produtiva, baseada na participação coletiva e valorização daquele que detinha maior conhecimento técnico aplicado sobre a realização construtiva - o próprio morador.

O habitat é tido, assim, não como uma finalidade em si, mas como potencializador de outras relações criadas localmente. O processo formativo se revela na forma de trabalho social, que por sua vez, se fundamenta enquanto princípio educativo.

A casa Suindara, para além de sua forma, se insere nas ações de melhoria da qualidade do habitat em comunidades rurais de reforma agrária, contribuindo com as práticas e reflexões sobre os processos contemporâneos de produção do habitat popular.

\section{Referências Bibliográficas}

ANDALOUSSI, Khalid El. Recherches-actions: sciences, développement, démocratie. Paris: Publisud, 2000.

BERGAMASCO, Sônia Maria; NORDER, Luiz AntonioCabello. O que são assentamentos 
rurais. São Paulo (SP): Editora Brasiliense, 1996.

CARNEIRO, Maria José; MALUF Renato Sérgio. Para além da produção: multifuncionalidade e agricultura familiar. Rio de Janeiro: MAUAD, 2003.

FERREIRA, Thiago Lopes, Arquiteturas vernáculas e processos contemporâneos de produção: Formação, experimentação e construção em um assentamento rural. Tese de doutorado em arquitetura. Grenoble: Universidade de Grenoble em cotutela com a Universidade de São Paulo, 2014.

FERRO, Sérgio. Arquitetura e trabalho livre. São Paulo (SP): Cosac Naify, 2006.

FINDELI, Alain; COSTE, Anne. De larecherchecréation à larecherche-projet: uncadrethéorique et méthodologiquepourlarecherchearchitecturale [en ligne]. 2007. [s.I.]: Lieuxcommuns, n`10. Disponiblesur :<http://hal.archives-

ouvertes.fr/hal-

0978330> (consulté le 29 septembre 2014).

FRANCO, Maria Amélia S. Pedagogia da Pesquisa-Ação. In: Educação e Pesquisa. set./dez. Vol. 31, n 3, p. p. 483- 502, 2005.

FREIRE, Paulo. Pedagogia da autonomia: saberes necessários à prática educativa. São Paulo (SP): Paz e Terra, 1997.

FREIRE, Paulo; FAUNDEZ, Antônio. Por uma pedagogia da pergunta. Rio de Janeiro (RJ): Paz e Terra, 1985.

FUNDAÇÃO JOÃO PINHEIRO, Centro de Estatística e Informações; et al. Déficit habitacional no Brasil: municípios selecionados e microrregiões geográficas. Belo Horizonte (MG): FundaçãoJoaão Pinheiro, Governo de Minas Gerais, 2013.

GUEGEN PERRIN, Anaïs, FERREIRA, Thiago Lopes. Maison Suindara, Chantier-écoledans une communautéruraleauBrésil = Casa Suindara, Canteiro-Escola em um assentamento rural de reforma agraria. Villefontaine: CRAterre. 48 p. ISBN 978-2906901-83-4, 2015.
INO, Akemi; SHIMBO, loshiaqui (coord.). O encontro de famílias e assessores: organizando grupos para projetos de habitação rural. Caixa Econômica Federal, 2007.

LEITE, Sérgio Pereira. Impactos dos assentamentos: um estudo sobre o meio rural brasileiro. Brasília; São Paulo: INSTITUTO NACIONAL DE COLONIZAÇÃO E REFORMA AGRÁRIA (NEAD); Ministério do Desenvolvimento Agrário (INCRA), Editora UNESP, 2004.

MARTINS, José de Souza. Os camponeses e a política no Brasil. Petrópolis (RJ): Vozes, 1986.

MOREIRA, Roberto José. Terra, poder e território. São Paulo: Expressão Popular, 2007.

VALADARES, Alexandre Arbex. O gigante invisível: território e população rural para além das convenções oficiais. Brasília (DF): IPEA. Coll. Texto para discussão, 2014.

WANDERLEY, Maria de Nazareth B. A ruralidade no Brasil moderno. Por un pacto social pelo desenvolvimento rural. In: GIARRACCA, Norma, Una nuevaruralidaden América Latina? [en ligne].

Argentina: CLACSO, Buenos Aires, 2001. Disponiblesur:http://bibliotecavirtual.clacso.org.a r/ar/libros/rural/wanderley.pdf > 